\title{
Nicotine Self-Administration Acutely Activates Brain Reward Systems and Induces a Long-Lasting Increase in Reward Sensitivity
}

\author{
Paul J Kenny' and Athina Markou*,I \\ 'Department of Neuropharmacology, The Scripps Research Institute, La Jolla, CA, USA
}

\begin{abstract}
Nicotine is a major component of tobacco smoke contributing to the initiation and persistence of the harmful tobacco habit in human smokers. The reinforcing effects of nicotine likely arise through its ability to stimulate brain circuitry mediating the detection and experiencing of natural rewards. Nevertheless, remarkably little is known concerning the acute or long-lasting actions of nicotine on brain reward systems in vivo. Here, we investigated the effects of intravenously self-administered nicotine $(0.03 \mathrm{mg} / \mathrm{kg} / \mathrm{infusion}$, free base) on the sensitivity of brain reward systems, reflected in alterations of intracranial self-stimulation (ICSS) thresholds in rats. Rats selfadministered nicotine during I or $12 \mathrm{~h}$ daily sessions, with reward thresholds assessed I h before and I 5 min after each self-administration session. Control rats remained nicotine naïve throughout. Nicotine self-administration increased the sensitivity of brain reward systems, detected by post-nicotine lowering of reward thresholds in $\mathrm{I}$ and $12 \mathrm{~h}$ rats. This nicotine-enhanced sensitivity of reward systems was reversed by the high-affinity nicotinic receptor antagonist dihydro- $\beta$-erythroidine $(\mathrm{DH} \beta \mathrm{E} ; 3 \mathrm{mg} / \mathrm{kg})$. Surprisingly, nicotine-induced excitation of reward systems persisted for at least 36 days after nicotine self-administration had ceased. Overall, these data demonstrate that rats can voluntarily consume quantities of nicotine sufficient to increase the sensitivity of brain reward systems, an action likely crucial in establishing and maintaining the nicotine habit. Moreover, self-administered nicotine resets the sensitivity of reward systems to a new increased level, thereby imprinting an indelible 'memory' of its effects in reward systems, an action that so far appears unique to nicotine among drugs of abuse.

Neuropsychopharmacology (2006) 31, 1203-121 I. doi: 10.1038/sj.npp. I 300905; published online 28 September 2005
\end{abstract}

Keywords: nicotine; self-administration; intracranial self-stimulation; reward; addiction

\section{INTRODUCTION}

It is generally accepted that tobacco-smoking behavior is at least partly a manifestation of nicotine addiction, and that nicotine is one of the most powerfully addictive drugs consumed by humans. The reinforcing actions of nicotine and other major drugs of abuse arise through their shared ability to usurp brain circuitry responsible for sensitivity to, learning about, and experiencing of natural rewards (Wise, 1996; Rice and Cragg, 2004). Moreover, adaptations that occur in brain reward circuits in response to their excessive, nonphysiological stimulation by drugs of abuse may contribute to the development of the compulsive drug use that characterizes addiction (Ahmed et al, 2002; Kenny et al, 2003). Hence, an understanding of the actions of nicotine

\footnotetext{
*Correspondence: Dr A Markou, Department of Neuropharmacology, CVN-7, The Scripps Research Institute, 10550 North Torrey Pines Road, La Jolla, CA 92037, USA, Tel: + I 858784 7244, Fax: + I 858 784 7405, E-mail: amarkou@scripps.edu

Received 3 May 2005; revised 19 July 2005; accepted 5 August 2005 Online publication: 22 August 2005 at http://www.acnp.org/citations/ Npp082205050281/default.pdf
}

on the activity of brain reward systems may illuminate mechanisms that drive nicotine addiction in human tobacco smokers. Nevertheless, remarkably little is known about the acute or long-lasting actions of nicotine on brain reward pathways.

The intracranial self-stimulation (ICSS) procedure provides an accurate measure of the sensitivity of brain reward systems in vivo (Kornetsky et al, 1979). In the ICSS procedure, rats respond vigorously to obtain rewarding electrical self-stimulation via a stimulating electrode implanted in various components of the brain's reward systems (Olds and Milner, 1954). By bypassing much of the input side of conventional natural reinforcers (feeding circuits, etc.) and directly activating brain reward systems, ICSS provides a unique tool to investigate the direct influence of drugs of abuse on brain reward systems. Indeed, rats demonstrate little satiation to ICSS during extended testing sessions (Olds, 1958). Repeated exposure to ICSS over days does not alter the baseline activity of brain reward systems (Annau et al, 1974), and prior exposure to ICSS does not alter patterns of intravenous drug self-administration (Markou and Koob, 1991; Ahmed et al, 
2002; Kenny et al, 2003). As such, ICSS is particularly useful for monitoring the effects of abuse drugs on brain reward systems across extended periods of time.

The minimal stimulation intensity that maintains ICSS behavior is termed the reward threshold (Kornetsky et al, 1979; Markou and Koob, 1992). Previously, experimenteradministered or self-administered infusions of various drugs of abuse such as psychomotor stimulants (Wise et al, 1977; Bauco and Wise, 1997; Kenny et al, 2003) and opiates (Bespalov et al, 1994) were shown to lower the reward threshold, indicating increased sensitivity to the rewarding effects of ICSS that likely arises through druginduced amplification of reward signals in the brain. Here, we directly investigated the short- and long-term actions of nicotine consumption on the sensitivity of brain reward systems in vivo by monitoring ICSS thresholds in rats with daily access to intravenous nicotine self-administration.

\section{MATERIALS AND METHODS}

\section{Subjects}

Subjects were 35 male Wistar rats weighing 300-320 g upon arrival at the laboratory. Rats were obtained from Charles River Laboratories (Raleigh, NC) and were housed in groups of two or three per cage. Animals were maintained in a temperature-controlled vivarium under a $12 \mathrm{~h}$ light/ dark cycle, with ad libitum access to food and water until ICSS training commenced. Animals received their daily nicotine self-administration session during the dark portion of the light/dark cycle. Animals had ICSS thresholds assessed at time points according to the experimental design. All animals were treated in accordance with the guidelines of the National Institutes of Health regarding the principles of animal care. Animal facilities and experimental protocols were in accordance with the Association for the Assessment and Accreditation of Laboratory Animal Care.

\section{Apparatus}

ICSS training and testing took place in 20 Plexiglas operant chambers $\left(25 \times 31 \times 24 \mathrm{~cm}^{3}\right.$; Med Associates, St Albans, VT). The floors of the operant chambers were constructed of parallel aluminum rods spaced $1.25 \mathrm{~cm}$ apart. One wall contained a metal wheel manipulandum that required $0.2 \mathrm{~N}$ force to rotate it one-quarter of a turn. The wheel $(5 \mathrm{~cm}$ in width) extended $\sim 3 \mathrm{~cm}$ out of the wall. Each testing chamber was enclosed within a light- and sound-attenuated chamber $\left(62 \times 63 \times 43 \mathrm{~cm}^{3}\right)$. Intracranial stimulation was delivered by constant current stimulators (Stimtech model 1200; San Diego Instruments, San Diego, CA). Subjects were connected to the stimulation circuit through flexible bipolar leads (Plastics One, Roanoke, VA) attached to gold-contact swivel commutators (model SL2C; Plastics One) mounted above the chamber. The stimulation parameters, data collection, and all test session functions were controlled by a microcomputer. Nicotine self-administration took place in 15 home-made metal and Plexiglas, soundattenuated operant chambers $\left(29 \times 24 \times 19.5 \mathrm{~cm}^{3}\right)$ with a floor constructed of aluminum rods spaced $1.3 \mathrm{~cm}$ apart. In each chamber, one wall contained two metal retractable levers, one 'active' and one 'inactive', that were mounted
$2.5 \mathrm{~cm}$ above the floor and required a $0.1 \mathrm{~N}$ force to be pressed. Plastic swivels (Plastics One Co., Roanoke, VA) connected the animals to syringes operated by Razel pumps that delivered the drug. Data collection and all programming functions were controlled by an IBM-compatible microcomputer.

\section{Surgery}

Rats were anesthetized by inhalation of $1-3 \%$ isoflurane in oxygen and positioned in a stereotaxic frame (Kopf Instruments, Tujunga, CA). The incisor bar was adjusted to $5 \mathrm{~mm}$ above the interaural line, and the skull was exposed. Stainless-steel bipolar electrodes (11 mm in length) were implanted into the posterior lateral hypothalamus (AP: $-0.5 \mathrm{~mm}$ from bregma; $\mathrm{ML}: \pm 1.7 \mathrm{~mm}$ from midline; DV: $8.3 \mathrm{~mm}$ from dura) according to the atlas of Pellegrino et al (1979). Four indentations were made in the skull to accommodate screws that, together with the application of dental acrylic, held the electrode in place. All rats were then prepared with catheters in the jugular vein as described previously (Caine and Koob, 1993). The catheter was passed subcutaneously to a polyethylene assembly mounted on the animal's back. This assembly consisted of a guide cannula (Plastic One Co., Roanoke, VA) attached to a $4 \mathrm{~cm}^{2}$ piece of marlex mesh with epoxy. The marlex mesh was placed under the skin on the animal's back.

\section{Procedure}

ICSS threshold. All rats (nicotine self-administering and control rats) were food restricted throughout the experiment to maintain them at $85 \%$ of their normal body weight obtained with free-feeding conditions. Rats were trained to respond according to a modification of the discrete-trial current-threshold procedure of Kornetsky and Esposito (1979), previously described in detail (Markou and Koob, 1992). Briefly, a trial was initiated by the delivery of a noncontingent electrical stimulus. This electrical reinforcer had a train duration of $500 \mathrm{~ms}$ and consisted of $0.1 \mathrm{~ms}$ rectangular cathodal pulses that were delivered at a frequency of $50-100 \mathrm{~Hz}$. The frequency of the stimulation was selected for individual animals so that current-intensity thresholds of each subject were within $50-200 \mu \mathrm{A}$, and thus allowed both threshold elevation or lowering to be detected. This frequency was held constant throughout the experiment. A one-quarter turn of the wheel manipulandum within $7.5 \mathrm{~s}$ of the delivery of the noncontingent electrical stimulation resulted in the delivery of an electrical stimulus identical in all parameters to the noncontingent stimulus that initiated the trial. After a variable intertrial interval $(7.5-12.5 \mathrm{~s}$, average of $10 \mathrm{~s})$, another trial was initiated with the delivery of a noncontingent electrical stimulus. Failure to respond to the noncontingent stimulus within $7.5 \mathrm{~s}$ resulted in the onset of the intertrial interval. Responding during the intertrial interval delayed the onset of the next trial by $12.5 \mathrm{~s}$. Current levels were varied in alternating descending and ascending series. A set of three trials was presented for each current-intensity. Current intensities were altered in $5 \mu \mathrm{A}$ steps. In each testing session, four alternating descending-ascending series were presented. The threshold for each series was defined as the midpoint 
between two consecutive current intensities that yielded 'positive scores' (animals responded for at least two of the three trials) and two consecutive current intensities that yielded 'negative scores' (animals did not respond for two or more of the three trials). The overall threshold of the session was defined as the mean of the thresholds for the four individual series. Each testing session was $\sim 30 \mathrm{~min}$ in duration.

Intravenous nicotine self-administration. All rats were trained to press an active lever for $45 \mathrm{mg}$ food pellets on a fixed-ratio 5 (FR5) time-out $20 \mathrm{~s}$ (TO20) schedule of reinforcement. Rats were also presented with an inactive lever during training sessions, responses on which were recorded but were without scheduled consequence. Rats were trained until stable responding for food was obtained, defined as $>90$ pellets per $1 \mathrm{~h}$ session. 1 and $12 \mathrm{~h}$ rats responded for nicotine on an FR5TO20s schedule of reinforcement, when five responses on the active lever resulted in the delivery of one nicotine injection $(0.03 \mathrm{mg} /$ $\mathrm{kg}$ /infusion dissolved in $0.1 \mathrm{ml}$ of sterile $0.9 \%$ sterile saline, free base) over $1 \mathrm{~s}$ duration, and initiated a $20 \mathrm{~s}$ time-out (TO) period signaled by a light cue located above the lever, during which responding on the lever was without consequence. Responding on the inactive lever during nicotine self-administration sessions was again recorded but was without scheduled consequence (data not presented).

\section{Experimental Procedure}

Rats were trained in the ICSS threshold procedure as described above once daily until stable reward thresholds were established, defined as $\leqslant 10 \%$ variation in thresholds for three consecutive days and requiring between 7 and 10 days. After the establishment of stable baseline thresholds, all rats had reward thresholds assessed twice daily for five consecutive days immediately prior to their first nicotine self-administration session to habituate them to multiple daily ICSS threshold assessments. On the two days immediately prior to their first nicotine self-administration session, rats were trained to lever press for food reinforcement as described above between the two daily ICSS threshold assessments, in order to accelerate acquisition of the lever press response for nicotine. Rats were then permitted to respond for intravenous nicotine infusions during 20 consecutive daily $1 \mathrm{~h}(1 \mathrm{~h}$ rats; $n=7)$ or $12 \mathrm{~h}(12 \mathrm{~h}$ rats; $n=8)$ self-administration sessions. Rats in $12 \mathrm{~h}$ sessions also had access to water during self-administration sessions.

Rats had reward thresholds assessed $1 \mathrm{~h}$ before (prethresholds) and 15-min after (post-thresholds) each daily nicotine self-administration session. Control rats $(n=5)$ remained nicotine naïve over the duration of the entire experiment and had thresholds assessed at time points similar to $12 \mathrm{~h}$ rats. To assess the role of high-affinity neuronal nicotinic acetylcholine receptor (nAChRs) in regulating the stimulatory actions of nicotine on brain reward systems, the effects of the high-affinity neuronal $\mathrm{nAChR}$ antagonist dihydro- $\beta$-erythroidine $(\mathrm{DH} \beta \mathrm{E})$ on nicotine-induced lowering of reward thresholds were examined. Control, 1 , and $12 \mathrm{~h}$ rats were injected with
$\mathrm{DH} \beta \mathrm{E} \quad(3 \mathrm{mg} / \mathrm{kg}$, salt) immediately after post-threshold assessment on day 15 of nicotine self-administration, and reward thresholds were immediately assessed for the third time that day. For comparison, rats were injected with saline immediately after post-threshold assessment on day 20, and reward thresholds were assessed.

After 20 consecutive days of access to nicotine selfadministration, rats were no longer permitted to selfadminister nicotine and remained in their home cages for the remainder of the experiment except for ICSS threshold assessment. Thresholds were assessed in the three groups of rats up to 8 days after the final nicotine self-administration session. As reward thresholds were unexpectedly lowered throughout the post-nicotine phase of the experiment in 1 and $12 \mathrm{~h}$ rats, we examined whether this effect could be replicated in a second cohort of control $(n=7), 1 \mathrm{~h}(n=4)$, and $12 \mathrm{~h}(n=4)$ rats. This second cohort of rats underwent the same experimental procedure outlined above for the first cohort of animals, with the exception that post-nicotine reward thresholds were assessed until 36 days in these rats. Only the data from the post-nicotine phase of the experiment are presented here for this second cohort of rats (Figure 4). Importantly, however, data collected during the nicotine self-administration phase in this second cohort of animals closely replicated the findings reported below.

\section{Statistical Analyses}

The number of nicotine infusions earned by 1 and $12 \mathrm{~h}$ rats during the 20 days of access to nicotine self-administration was analyzed by two-way repeated-measures analysis of variance (ANOVA), with Access ( 1 or $12 \mathrm{~h}$ ) as a betweensubjects factor and Days as a within-subjects repeatedmeasures factor. For ICSS data, percentage change from baseline reward thresholds was calculated by expressing the reward threshold scores during the nicotine self-administration phase of the experiment (including the assessment of the effects of $\mathrm{DH} \beta \mathrm{E}$ ), and the post-nicotine phase of the experiment as a percentage of baseline thresholds, minus 100. The baseline reward thresholds were the mean thresholds obtained for each rat on the five ICSS sessions prior to the first nicotine self-administration session. During the nicotine self-administration phase of the experiment, threshold scores for control, 1 , or $12 \mathrm{~h}$ rats were analyzed with three-factor repeated measures ANOVA, with Session (pre-thresholds or post-thresholds) as a within-subjects factor, Days as a within-subjects repeated-measures factor, and Access (control, 1 or $12 \mathrm{~h}$ ) as a between-subjects factor. This analysis was followed by individual two-factor repeated-measures ANOVAs for control, 1, and $12 \mathrm{~h}$ rats, with Session (pre-thresholds or post-thresholds) as a withinsubjects factor and Days as a within-subjects repeatedmeasures factor. To investigate the effects of $\mathrm{DH} \beta \mathrm{E}$ on nicotine-induced lowering of reward thresholds, pre-thresholds, post-thresholds, and post- $\mathrm{DH} \beta \mathrm{E}$ thresholds on day 15 , and pre-thresholds, post-thresholds, and post-saline thresholds on day 20 , for control, 1 , and $12 \mathrm{~h}$ rats were analyzed by three-way repeated-measures ANOVA. Factors for this analysis were Access (control, 1 or $12 \mathrm{~h}$ ) as a betweensubjects factor, Drug (saline or $\mathrm{DH} \beta \mathrm{E}$ ) as a within-subjects factor, and Session (pre-thresholds, post-thresholds, and 
post-DH $\beta \mathrm{E} /$ saline thresholds) as a within-subjects repeatedmeasures factor. Reward thresholds for control, 1 and $12 \mathrm{~h}$ rats during the post-nicotine phase of the experiment were analyzed by two-factor repeated-measures ANOVA, with prior Access as a between-subjects factor and Days as a within-subjects repeated-measures factor. After statistically significant effects in the ANOVAs, post hoc comparisons among means were conducted with Fisher's LSD test. The level of significance was set at 0.05 .

\section{RESULTS}

\section{Nicotine Self-Administration in Rats with Restricted or Extended Access to Nicotine}

Stable patterns of daily nicotine intake were rapidly established in rats with 1 or $12 \mathrm{~h}$ daily access to nicotine self-administration (Figure 1a). As expected, rats with $12 \mathrm{~h}$
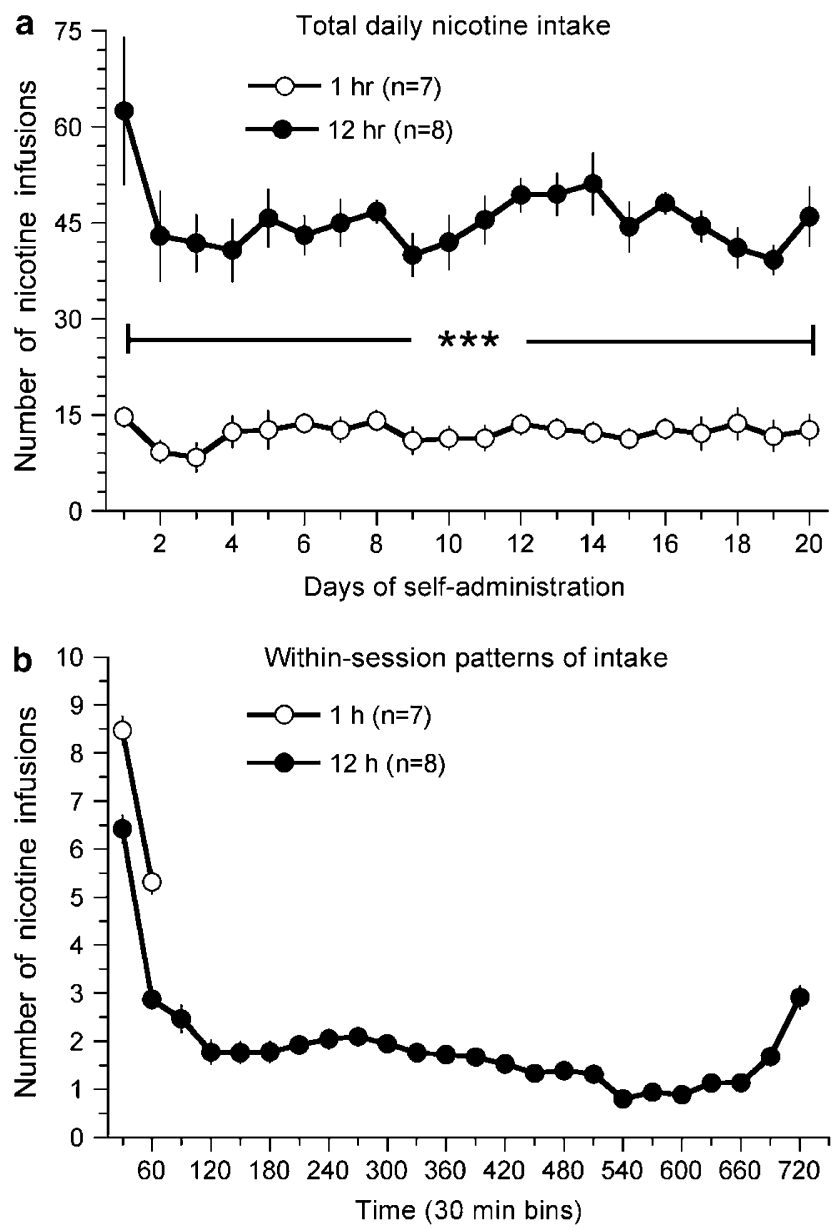

Figure I Nicotine self-administration increases the sensitivity of brain reward systems. (a) Daily nicotine intake in rats with limited $(\mathrm{I} \mathrm{h})$ or extended $(12 \mathrm{~h}$ ) daily access to nicotine self-administration. Mean number of nicotine infusions $( \pm$ SEM) earned each day by rats with I or $12 \mathrm{~h}$ daily access to nicotine $\left(0.03 \mathrm{mg} / \mathrm{kg} /\right.$ infusion; free-base). ${ }^{*} * * p<0.00 \mathrm{l}$, main effect of access ( 1 or $12 \mathrm{~h}$ ) on the nicotine doses consumed, two-way repeated measures ANOVA. (b) Within-session number of nicotine infusions earned over the entire 20 days of access to nicotine. Mean infusions $( \pm$ SEM) earned by $\mathrm{I}$ and $12 \mathrm{~h}$ rats are presented in 30 min time bins. daily access to nicotine consumed greater quantities of nicotine $(\sim 1.36 \mathrm{mg} / \mathrm{kg} /$ day $)$ than rats with $1 \mathrm{~h}$ daily access ( $\sim 0.38 \mathrm{mg} / \mathrm{kg} /$ day) (Figure 1a; main effects of Access $\left(\mathrm{F}_{(1,13)}=154.9, \quad p<0.001\right)$, Days $\left(\mathrm{F}_{(13,19)}=3.5, p<0.001\right)$, and Access $\times$ Days interaction $\left(\mathrm{F}_{(19,247)}=3.0, p<0.001\right)$. In addition to stable daily nicotine intake, 1 and $12 \mathrm{~h}$ rats also established stable patterns of within-session nicotine intake, as reflected in the number of nicotine infusions earned during $30 \mathrm{~min}$ bins in each self-administration session over the entire 20 sessions (Figure $1 \mathrm{~b}$ ). Intake in $1 \mathrm{~h}$ rats was characterized by a 'loading' phase during the first $30 \mathrm{~min}$ of the $1 \mathrm{~h}$ session, with less nicotine being consumed during the final $30 \mathrm{~min}$ of each session (Figure $1 \mathrm{~b}$ ). In $12 \mathrm{~h}$ rats, intake was characterized by an initial loading phase during the first $30 \mathrm{~min}$; this was followed by a 'maintenance' phase where rats self-administered between one and two infusions every $30 \mathrm{~min}$ for approximately $10 \mathrm{~h}$; finally, nicotine intake increased during the last $30 \mathrm{~min}$ of each $12 \mathrm{~h}$ session, when rats consumed approximately three infusions (Figure 1b).

\section{Nicotine Self-Administration Increases the Sensitivity of Brain Reward Systems}

Mean absolute baseline reward thresholds in control, 1, and $12 \mathrm{~h}$ rats were $116.4 \pm 12.0,105.9 \pm 5.9$, and $113.5 \pm 13.1 \mu \mathrm{A}$, respectively. Self-administration of nicotine significantly lowered post-thresholds in 1 and $12 \mathrm{~h}$ rats, reflected in a statistically significant effect of Access $\left(\mathrm{F}_{(2,17)}=9.3\right.$, $p<0.01)$, Session $\left(\mathrm{F}_{(1,17)}=59.8, p<0.001\right)$, Days $\left(\mathrm{F}_{(19,323)}=4.8\right.$, $p<0.001)$, and a significant Access $\times$ Days $\times$ Session interaction effect $\left(\mathrm{F}_{(38,323)}=1.6, p<0.05\right)$. Further analysis of the main effect of Session demonstrated that reward thresholds were significantly lowered in $1 \mathrm{~h}$ rats compared with control $(p<0.001)$ and $12 \mathrm{~h}$ rats $(p<0.05)$.

To further analyze the effects of nicotine on thresholds, individual two-factor ANOVAs were carried out for control, 1 , and $12 \mathrm{~h}$ rats. Reward thresholds remained stable and unaltered over the duration of the entire experiment in control rats at both daily time points of assessment (Figure 2a) (Session $\left(\mathrm{F}_{(1,4)}=0.01, \mathrm{NS}\right)$; Days $\left(\mathrm{F}_{(19,76)}=0.5\right.$, NS); Session $\times$ Days interaction $\left(\mathrm{F}_{(19,76)}=1.1\right.$, NS)). In contrast, nicotine self-administration lowered post-thresholds in $1 \mathrm{~h}$ rats (Figure $2 \mathrm{~b}$ ), reflected in statistically significant effects of Session $\left(\mathrm{F}_{(1,6)}=39.8, p<0.001\right)$ and Days $\left(\mathrm{F}_{(19,114)}=8.9, p<0.001\right)$ (Figure $\left.2 \mathrm{~b}\right)$. There was a marked downward shift in daily pre-thresholds and postthresholds in $1 \mathrm{~h}$ rats that progressively increased in magnitude as days of exposure to nicotine increased (Figure 2b). Analysis of pre-thresholds over Days from $1 \mathrm{~h}$ rats demonstrated a significant lowering of pre-thresholds as exposure to nicotine increased $\left(\mathrm{F}_{(19,114)}=7.3, p<0.001\right)$; pre-thresholds were significantly lowered on days 3,7 , and 9-20 compared with pre-thresholds obtained on day 1 (Figure 2b). Nicotine self-administration significantly lowered post-thresholds in $12 \mathrm{~h}$ rats (Figure $2 \mathrm{c}$ ), reflected in statistically significant effects of Session $\left(\mathrm{F}_{(1,7)}=53.5\right.$, $p<0.001)$ and Days $\left(\mathrm{F}_{(19,133)}=2.0, p<0.05\right)$. In contrast to $1 \mathrm{~h}$ rats, however, pre-nicotine thresholds remained stable and unaltered over Days in the $12 \mathrm{~h}$ rats $\left(\mathrm{F}_{(19,133)}=1.0, \mathrm{NS}\right.$; Figure 2c). 

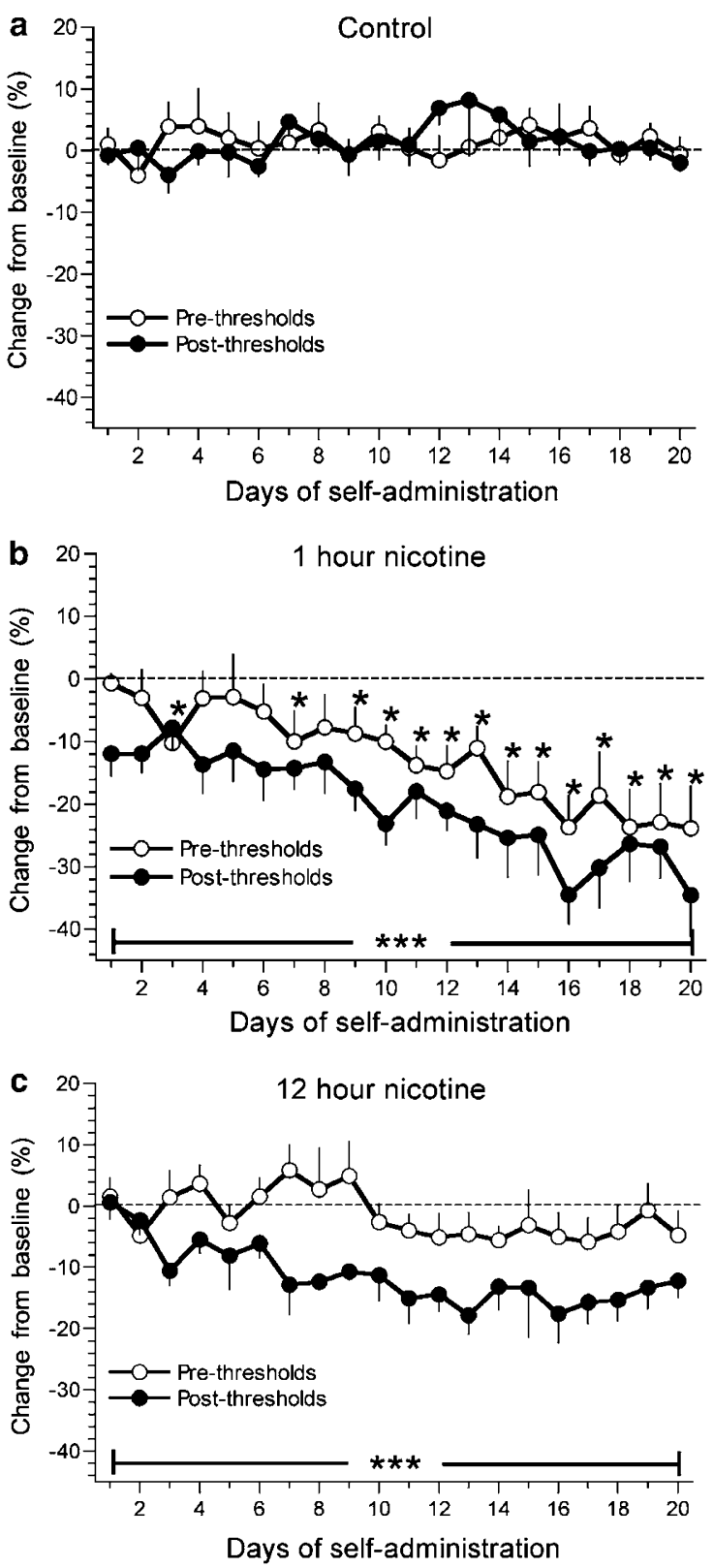

Figure 2 Nicotine self-administration increases the sensitivity of brain reward systems. (a) Daily pre-nicotine and post-nicotine reward thresholds $( \pm$ SEM) remained stable and unaltered in nicotine-naïve control rats. (b) Daily post-thresholds $( \pm$ SEM), assessed $15 \mathrm{~min}$ after each daily nicotine self-administration session, were lowered compared with pre-thresholds $( \pm$ SEM), assessed I h before each self-administration session, in I $\mathrm{h}(n=7)$ rats. ${ }^{* * *} p<0.001$, main effect of nicotine on reward thresholds, two-way repeated measures ANOVA. In addition, there was a progressive lowering of pre-thresholds in I h rats that resulted in a gradual downward shift in both pre-thresholds and post-thresholds. ${ }^{*} p<0.05$, compared with prethresholds obtained prior to the first nicotine self-administration session (day I), post-hoc test after one-way ANOVA. (c) Daily post-thresholds $( \pm$ SEM) were lowered compared with pre-nicotine thresholds $( \pm$ SEM) in $12 \mathrm{~h}(n=8)$ rats. ${ }^{*} * * * 0.00 \mathrm{I}$, main effect of nicotine on reward thresholds, two-way repeated measures ANOVA.

\section{High-Affinity Nicotinic Receptors Regulate Nicotine's Actions on Brain Reward Systems}

The high-affinity nAChR antagonist $\mathrm{DH} \beta \mathrm{E}$, but not saline, reversed the lowering of post-thresholds in 1 and $12 \mathrm{~h}$ rats induced by self-administered nicotine, reflected in a statistically significant effect of Access $\left(\mathrm{F}_{(2,17)}=7.9, p<0.01\right)$, Drug $\left(\mathrm{F}_{(1,2)}=8.2, \quad p<0.05\right)$, and Session $\left(\mathrm{F}_{(2,4)}=21.6\right.$, $p<0.001)$. An Access $\times$ Days $\times$ Session interaction effect approaching significance was also observed $\left(\mathrm{F}_{(38,323)}=2.3\right.$, $p=0.078, \mathrm{NS}$ ) (Figure 2). In keeping with our hypothesis that $\mathrm{DH} \beta \mathrm{E}$ would block the effects of nicotine on thresholds, post hoc analyses demonstrated that post-thresholds were significantly lowered compared with pre-thresholds in $1 \mathrm{~h}(p<0.05)$ and $12 \mathrm{~h}$ rats $(p<0.01)$ on days 15 and 20 , while $\mathrm{DH} \beta \mathrm{E}$ administration on day 15 , but not saline on day 20, attenuated this nicotine-induced lowering of reward thresholds (Figure 3).

\section{Nicotine Induces a Persistent Increase in the Sensitivity of Brain Reward Systems}

Two-way repeated-measures ANOVA demonstrated a main effect of prior nicotine access on reward thresholds during the post-nicotine phase of the experiment, reflected in a significant effect of Access $\left(\mathrm{F}_{(2,17)}=6.0, p<0.01\right)$, no effect of Days $\left(\mathrm{F}_{(8,16)}=1.5, \mathrm{NS}\right)$, and no significant Access $\times$ Days interaction effect $\left(\mathrm{F}_{(16,136)}=1.2\right.$, NS). Test of the simple main effect of Access demonstrated that during the postnicotine phase of the experiment, reward thresholds of $1 \mathrm{~h}$ and $12 \mathrm{~h}$ rats were lowered compared with control rats $(p<0.01 ; p<0.05$, respectively), and the magnitude of this effect was similar in 1 and $12 \mathrm{~h}$ rats $(p=0.14, N . S$. $)$ (Figure 4).

To replicate the unexpected observation that reward thresholds were lowered throughout the post-nicotine phase of the experiment in 1 and $12 \mathrm{~h}$ rats, and to examine the persistence of this phenomenon, reward thresholds were assessed in a second cohort of control, 1 , and $12 \mathrm{~h}$ rats. Reward thresholds were assessed in this second set of rats for 36 days after their final nicotine self-administration session. Analysis of post-nicotine reward thresholds from these subjects again demonstrated a significant effect of prior access to nicotine, reflected in a significant effect of Access $\left(\mathrm{F}_{(2,12)}=7.9, p<0.01\right)$, no effect of Days $\left(\mathrm{F}_{(19,38)}=0.7\right.$, NS), and no significant Access $\times$ Days interaction effect $\left(\mathrm{F}_{(38,228)}=0.6\right.$, NS). Test of the simple main effect of Access demonstrated that reward thresholds remained significantly lowered in $1(p<0.05)$ and $12 \mathrm{~h}$ $(p<0.01)$ rats during the entire 36-day post-nicotine period compared with control rats (Figure 5).

\section{DISCUSSION}

Similar to other major drugs of abuse, experimenteradministered bolus nicotine injections increase the sensitivity of brain reward systems, reflected in lowered brain reward thresholds (Harrison et al, 2002). Here, we show that rats volitionally consume quantities of nicotine during 1 or $12 \mathrm{~h}$ self-administration sessions sufficient to increase the sensitivity of brain reward systems, and thereby amplify the rewarding effects of ICSS. Thus, achieving maximal increases in the sensitivity of brain reward systems may be a crucial factor in determining the amount of nicotine selfadministered, and its pattern of intake. Unexpectedly, however, the stimulatory action of nicotine on reward 

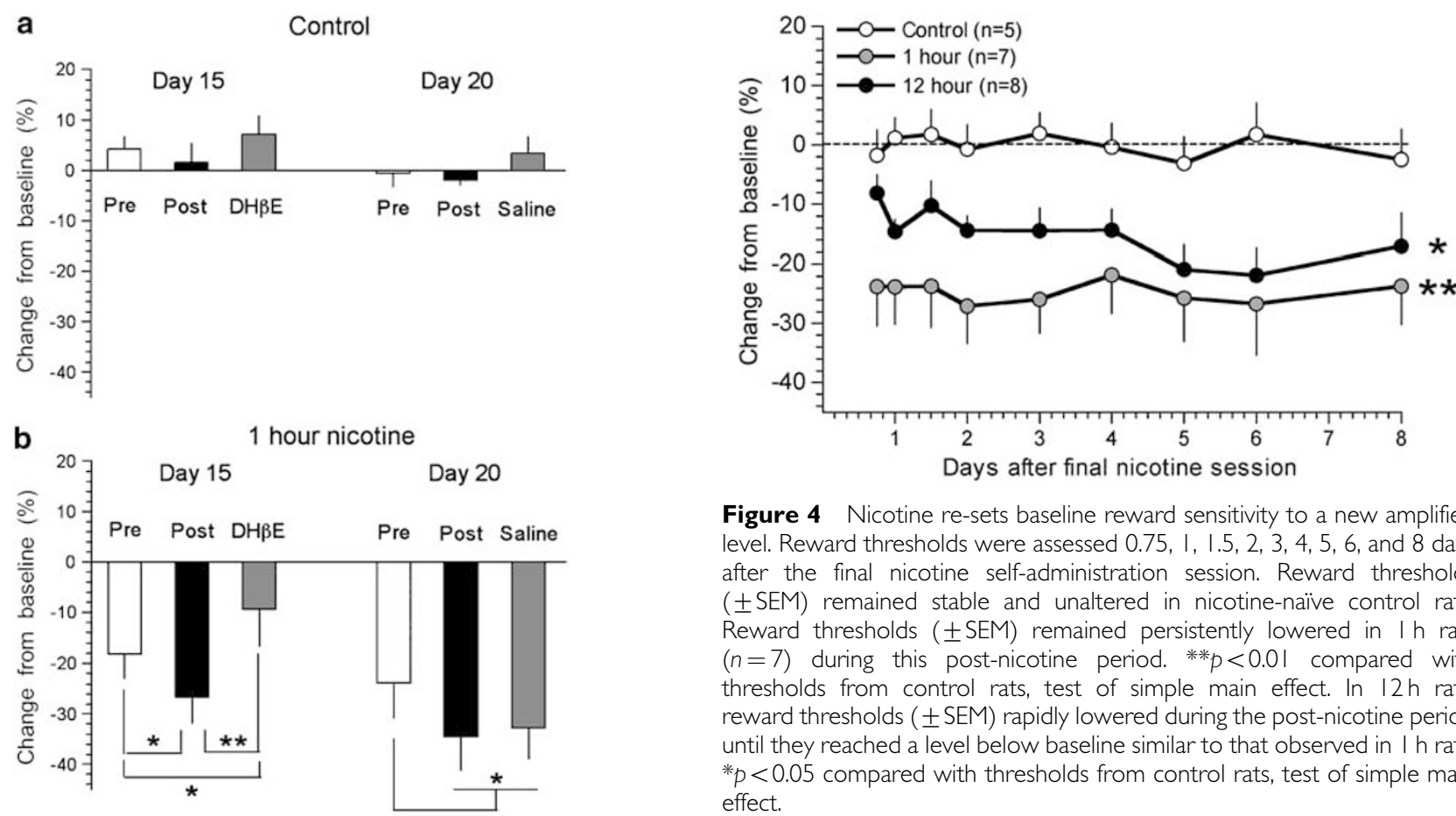

Figure 4 Nicotine re-sets baseline reward sensitivity to a new amplified level. Reward thresholds were assessed 0.75, I, I.5, 2, 3, 4, 5, 6, and 8 days after the final nicotine self-administration session. Reward thresholds $( \pm S E M)$ remained stable and unaltered in nicotine-naïve control rats. Reward thresholds $( \pm S E M)$ remained persistently lowered in $I \mathrm{~h}$ rats $(n=7)$ during this post-nicotine period. $* * * 0.01$ compared with thresholds from control rats, test of simple main effect. In $12 \mathrm{~h}$ rats, reward thresholds $( \pm$ SEM) rapidly lowered during the post-nicotine period until they reached a level below baseline similar to that observed in I $\mathrm{h}$ rats. * $p<0.05$ compared with thresholds from control rats, test of simple main effect.

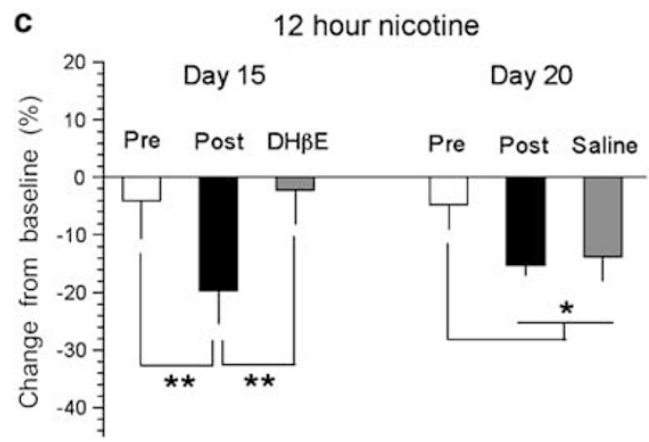

Figure 3 The competitive nicotinic receptor antagonist $\mathrm{DH} \beta \mathrm{E}$ reversed the increased sensitivity of brain reward systems induced by selfadministered nicotine. Pre-thresholds (Pre), post-thresholds (post), and post- $\mathrm{DH} \beta \mathrm{E}$ thresholds $(\mathrm{DH} \beta \mathrm{E})$ or post-saline thresholds (saline) were assessed on days 15 and 20 of nicotine self-administration. (a) Reward thresholds $( \pm$ SEM) were unaltered by injection of $\mathrm{DH} \beta \mathrm{E}$ on day I5 (left panel) or saline on day 20 (right panel) in nicotine-naïve control rats. (b) Injection of $\mathrm{DH} \beta \mathrm{E}$ reversed the lowering of post-thresholds compared with pre-thresholds observed on day I5 (left panel) in I h rats. Saline injection did not reverse the lowering of post-thresholds compared with prethresholds observed on day 20 (right panel) in I h rats. $* p<0.05$, ** $p<0.0$ l, post hoc test after three-way ANOVA. (c) Injection of $\mathrm{DH} \beta \mathrm{E}$ reversed the lowering of post-thresholds compared with pre-thresholds on day 15 (left panel) in $12 \mathrm{~h}$ rats. Saline injection did not reverse the lowering of post-thresholds compared with pre-thresholds on day 20 (right panel) in $12 \mathrm{~h}$ rats. $* p<0.05, * * p<0.01$, post hoc test after three-way ANOVA.

systems was very long lasting, as reward thresholds remained persistently lowered in 1 and $12 \mathrm{~h}$ rats during the entire post-nicotine assessment period when rats no longer had access to nicotine self-administration. Thus, selfadministered nicotine induces a persistent amplification in the brain's sensitivity to rewarding stimuli, an action of nicotine that appears fundamentally different from the long-term actions of other drugs of abuse such as cocaine (Markou and Koob, 1991; Ahmed et al, 2002; Kenny et al, 2003) or heroin (Kenny, Chen, Markou, and Koob,

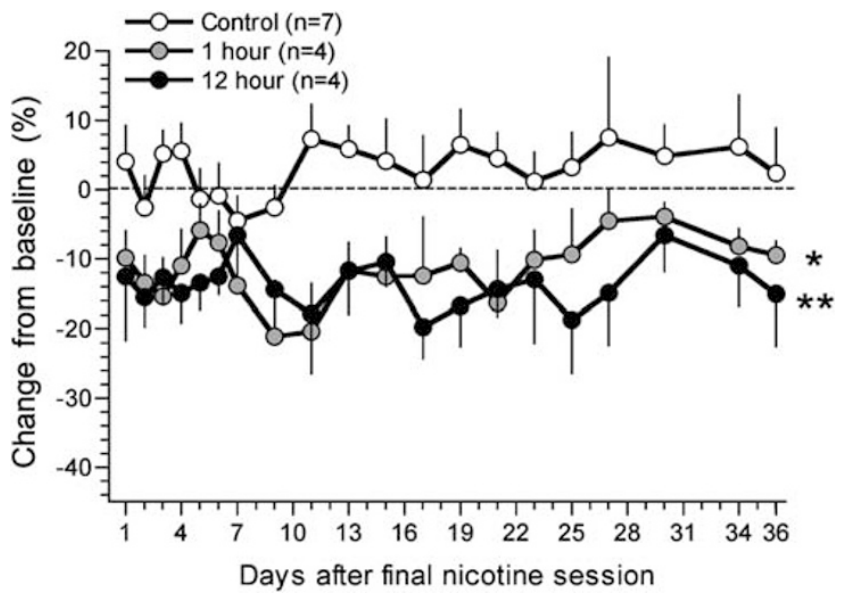

Figure 5 Nicotine-induced increases in reward sensitivity are very long lasting. Reward thresholds were assessed in a second cohort of control, I, and $12 \mathrm{~h}$ rats until 36 days after the final nicotine self-administration session. Reward thresholds $( \pm$ SEM) remained stable and unaltered in nicotinenaive control rats. Reward thresholds $( \pm S E M)$ remained persistently lowered in $\mathrm{I}$ and $12 \mathrm{~h}$ rats during this post-nicotine period. $* \mathrm{p}<0.05 \mathrm{Ih}$ rats compared with control rats, $* * p<0.0112 \mathrm{~h}$ rats compared with control rats, test of simple main effects.

unpublished observations) that usually results in long-term compensatory decreases in the activity of brain reward systems during the early abstinence period.

The present data may account for some of the unusual properties of nicotine compared with other drugs of abuse. For example, extended access to cocaine (Ahmed and Koob, 1998; Ahmed et al, 2002) or morphine (Ahmed et al, 2000) self-administration results in a progressive 'escalation' in drug intake reminiscent of the compulsively increased drug intake in human drug addicts, an effect not observed with 
extended access to nicotine (Figure 1a). Moreover, schedules of access to cocaine and other drugs of abuse that result in escalated drug intake also result in decreases of reward sensitivity, which presumably arise to counter the reward-facilitating actions of these drugs (Ahmed et al, 2002; see also Markou and Koob, 1991; Kenny et al, 2003). Thus, escalated intake of cocaine and other addictive drugs likely develops to counter progressive reward deficits associated with extended drug access. The observations above suggest that nicotine consumption does not escalate over time because a similar progressive reward deficit does not develop with extended periods of nicotine self-administration, at least not under the present conditions.

It is interesting to note that spontaneous or $\mathrm{nAChR}$ antagonist-precipitated withdrawal from nicotine delivered via chronic indwelling subcutaneous osmotic mini-pumps, as opposed to self-administration, induced elevations of reward thresholds above pre-nicotine baseline levels similar to the threshold elevations observed after cessation of cocaine self-administration (Epping-Jordan et al, 1998; Watkins et al, 2000). Thus, volitional nicotine consumption may induce adaptations in reward circuitries different from those produced by passively administered nicotine, or selfadministration of other drugs of abuse. Consistent with this hypothesis, nicotine induced long-term potentiation of excitatory inputs to reward areas in the rat brain that persisted long after nicotine was no longer present (Mansvelder and McGehee, 2000). It is important to note, however, that the amounts of nicotine self-administered during the 1 or $12 \mathrm{~h}$ sessions in the present studies (approximately 0.38 and $1.36 \mathrm{mg} / \mathrm{kg}$ nicotine free base per day, respectively) were significantly less than the daily amounts delivered by a mini-pump in the studies described above $(3.16 \mathrm{mg} / \mathrm{kg}$ nicotine per day). Thus, it is possible that access to nicotine self-administration for durations longer than the 20 days reported here may induce further adaptations in brain reward systems similar to those observed in rats treated with nicotine via mini-pumps, and in cocaine self-administering rats. Nevertheless, repeated 1 or $6 \mathrm{~h}$ daily access to nicotine self-administration was recently shown to induce 'physical' dependence on nicotine, such that a spontaneous somatic withdrawal syndrome was observed $23 \mathrm{~h}$ after cessation of nicotine intake (Paterson and Markou, 2004). Thus, although somatic signs of spontaneous withdrawal were not investigated in the present study, it is likely that 'physical' dependence on nicotine developed in parallel with the reward hypersensitivity reported here. Overall, the present findings offer the intriguing possibility that volitional nicotine consumption induces long-lasting adaptations in reward pathways fundamentally different from those produced by other drugs of abuse such as cocaine or by higher doses of passively experimenter-administered nicotine. However, to fully explore the above hypothesis it will be necessary to examine the sensitivity of brain reward systems in 'yoked' control rats that passively receive a pattern of nicotine infusions similar to that observed in rats that volitionally self-administer nicotine infusions.

Accumulating evidence suggests that $\alpha 4$ - and $\beta 2$-containing $\mathrm{nAChRs}$ may play a crucial role in regulating the stimulatory effects of nicotine on brain reward systems. For example, similar rates of intravenous cocaine self- administration were observed in wild-type and mutant mice in which the $\beta 2 \mathrm{nAChR}$ subunit had been null mutated $\left(\beta 2^{-I-}\right.$ mice). However, when cocaine was substituted with nicotine, wild-type mice persisted in responding to nicotine, whereas $\beta 2^{-l-}$ mice rapidly extinguished responding (Picciotto et al, 1998; Epping-Jordan et al, 1999). Most recently, $\alpha 4$ knock-in mice, bearing a mutation that rendered $\alpha 4$-containing receptors hypersensitive to nicotine, demonstrated a nicotine-induced conditioned place preference at nicotine doses 50-fold lower than those necessary to induce a place preference in wild-type mice (Tapper et al, 2004). Overall, these observations provide strong evidence that $\alpha 4$ - and $\beta 2$-containing nAChRs mediate the effects of nicotine on brain reward systems (Picciotto et al, 1997; Tapper et al, 2004). In the present studies, we show that $\mathrm{DH} \beta \mathrm{E}$ reversed nicotine-induced lowering of reward thresholds. $\mathrm{DH} \beta \mathrm{E}$ is considered relatively selective for $\alpha 4 \beta 2$ high-affinity nAChRs (Harvey and Luetje, 1996; Harvey et al, 1996), although the selectivity of $\mathrm{DH} \beta \mathrm{E}$ and other $\mathrm{nAChR}$ antagonists for specific nAChR subtypes is poor (Damaj et al, 1995; Harvey and Luetje, 1996; Harvey et al, 1996). Nevertheless, these data are consistent with an important role for high-affinity, possibly $\alpha 4 \beta 2$, nAChRs in regulating the stimulatory actions of self-administered nicotine on brain reward systems.

In the present studies, we observed a progressive downward shift in baseline reward thresholds in $1 \mathrm{~h}$ rats during the 20 days of self-administration, suggesting that this schedule of access to nicotine induced a progressively greater increase in the sensitivity of brain reward systems. Curiously, a similar downward shift of reward thresholds did not emerge in $12 \mathrm{~h}$ rats during the nicotine self-administration phase of the experiment (Figure 2c). Importantly, however, reward thresholds were similarly lowered in 1 and $12 \mathrm{~h}$ rats during the post-nicotine phase of the experiment (see Figures 4 and 5). Thus, it is likely that similar long-lasting adaptations were manifest in the reward systems of 1 and $12 \mathrm{~h}$ rats, but that these adaptations were not apparent in $12 \mathrm{~h}$ rats until nicotine was unavailable for self-administration for periods greater than the $12 \mathrm{~h}$ between each self-administration session. The precise mechanism that accounts for the above pattern of effects is unclear. It is unlikely, however, that repeated daily exposure to the ICSS procedure contributed to the increased sensitivity in reward systems reported here because control rats, that also had ICSS thresholds assessed twice daily, demonstrated stable and unaltered reward thresholds across days. One possible mechanism that may account for the present observations is that nAChRs located in brain reward systems become desensitized and subsequently upregulated during repeated 1 and $12 \mathrm{~h}$ daily nicotine self-administration sessions. Indeed, it was recently shown that nicotine self-administration up-regulated nAChRs throughout the rat brain (Parker et al, 2004). Thus, when nicotine is unavailable for self-administration during extended periods of time, such as the $23 \mathrm{~h}$ between each self-administration session in $1 \mathrm{~h}$ rats or during the post-nicotine phase of the experiment in 1 and $12 \mathrm{~h}$ rats, nAChRs may recover from nicotine-induced desensitization and enter a state of hyperactivity, inducing hyperexcitability of brain reward systems. By a similar line of reasoning, nAChRs located in brain circuits that regulate other behavioral aspects of 
self-administered nicotine, such as its anxiogenic effects (Irvine et al, 2001), may also become hyperactive after cessation of nicotine intake, contributing to the wellcharacterized aversive syndrome observed in human smokers during extended periods of nicotine abstinence.

The hypersensitivity of brain reward systems that emerged during the post-nicotine phase of the experiment closely resembles the reward hypersensitivity that emerges in food-restricted rats undergoing a period of negative energy balance (Blundell and Herberg, 1968; Carr and Wolinsky, 1993; Carr, 1996; Lin et al, 2002). This reward hypersensitivity during food deprivation is hypothesized to increase the appetitive value of food and thereby drive food intake (Herberg and Blundell, 1967; Fulton et al, 2000). Thus, it is possible that the reward hypersensitivity during nicotine deprivation may be analogous, albeit maladaptive, to that observed in food-deprived rats, increasing the appetitive value of nicotine and perpetuating the nicotine habit. A number of other possible consequences of the longlasting stimulatory action of nicotine on reward pathways may also be postulated. Nicotine-induced reward hypersensitivity may potentiate the effects of other drug reinforcers, and thereby account for the high incidence of nicotine consumption in conjunction with other drugs of abuse such as alcohol (Hughes, 1994) or caffeine (Brown and Benowitz, 1989; Shoaib et al, 1999). In addition, nicotine-induced reward hypersensitivity may potentiate the effects of nondrug, natural reinforcers. Such an action could potentially contribute to the increased food intake, and subsequent weight gain often observed in abstinent human smokers. In addition, nicotine-induced potentiation of nondrug reinforcers may help explain recent observations that nicotine facilitates reward-related learning (Olausson et al, 2003), increases responding for a conditioned reinforcer previously paired with water reward (Olausson et al, 2004a,b), potentiates responding for a natural (visual) reinforcer (Donny et al, 2003), and accounts for the long-lasting motivational effects of nicotine-associated conditioned reinforcers (Cohen et al, 2005). The reward hypersensitivity that persists after nicotine intake has ceased may also serve as a powerful interoceptive discriminative stimulus. Indeed, relapse to the smoking habit can occur after many years of abstinence, suggesting that enduring nicotine-induced adaptations may persist in the brains of smokers. Thus, it is possible that reward hypersensitivity in abstinent human smokers acts as a persistent 'memory' in reward pathways of the effects of nicotine, which provokes relapse even after long periods of smoking abstinence.

In summary, nicotine self-administration increased the sensitivity of brain reward systems, and this action of nicotine persisted for at least 36 days after nicotine intake had ceased. Acute nicotine consumption stimulates reward pathways in a manner similar to other drugs of abuse, a factor likely essential in establishing and maintaining the tobacco-smoking habit in humans. However, nicotine may imprint an indelible 'memory' in brain reward pathways by resetting their sensitivity to a new increased level, a property that so far appears unique to nicotine among drugs of abuse. Overall, these data represent a fundamental departure from previous conceptualizations of the longterm actions of nicotine on brain reward systems, and provide a novel framework for understanding the motivational drives that contribute to tobacco addiction in humans.

\section{ACKNOWLEDGEMENTS}

This work was supported by the National Association for Research on Schizophrenia and Depression (NARSAD; PJK), and the Tobacco Related Disease Research Program from the State of California (12RT-0231; AM). We thank Drs Stephanie Caille and Marisa Roberto for helpful comments on an earlier version of the manuscript. We are especially grateful to $\mathrm{Mr}$ Michael Arends for insightful comments and discussions, and for help with manuscript preparation. This is publication number 16692-NP from The Scripps Research Institute.

\section{REFERENCES}

Ahmed SH, Kenny PJ, Koob GF, Markou A (2002). Neurobiological evidence for hedonic allostasis associated with escalating cocaine use. Nat Neurosci 5: 625-626.

Ahmed SH, Koob GF (1998). Transition from moderate to excessive drug intake: change in hedonic set point. Science 282: 298-300.

Ahmed SH, Walker JR, Koob GF (2000). Persistent increase in the motivation to take heroin in rats with a history of drug escalation. Neuropsychopharmacology 22: 413-421.

Annau Z, Heffner R, Koob GF (1974). Electrical self-stimulation of single and multiple loci: long term observations. Physiol Behav 13: 281-290.

Bauco P, Wise RA (1997). Synergistic effects of cocaine with lateral hypothalamic brain stimulation reward: lack of tolerance or sensitization. J Pharmacol Exp Ther 283: 1160-1167.

Bespalov A, Dumpis M, Piotrovsky L, Zvartau E (1994). Excitatory amino acid receptor antagonist kynurenic acid attenuates rewarding potential of morphine. Eur J Pharmacol 264: 233-239.

Blundell JE, Herberg LJ (1968). Relative effects of nutritional deficit and deprivation period on rate of electrical self-stimulation of lateral hypothalamus. Nature 219: 627-628.

Brown CR, Benowitz NL (1989). Caffeine and cigarette smoking: behavioral, cardiovascular, and metabolic interactions. Pharmacol Biochem Behav 34: 565-570.

Caine B, Koob GF (1993). Intravenous drug self-administration techniques in animals. In: Sahgal A (ed). Behavioural Neuroscience: A Practical Approach. IRL Press: Oxford. pp 117-143.

Carr KD (1996). Feeding, drug abuse, and the sensitization of reward by metabolic need. Neurochem Res 21: 1455-1467.

Carr KD, Wolinsky TD (1993). Chronic food restriction and weight loss produce opioid facilitation of perifornical hypothalamic self-stimulation. Brain Res 607: 141-148.

Cohen C, Perrault G, Griebel G, Soubrie P (2005). Nicotineassociated cues maintain nicotine-seeking behavior in rats several weeks after nicotine withdrawal: reversal by the cannabinoid (CB1) receptor antagonist, rimonabant (SR141716). Neuropsychopharmacology 30: 145-155.

Damaj MI, Welch SP, Martin BR (1995). In vivo pharmacological effects of dihydro-beta-erythroidine, a nicotinic antagonist, in mice. Psychopharmacology (Berl) 117: 67-73.

Donny EC, Chaudhri N, Caggiula AR, Evans-Martin FF, Booth S, Gharib MA et al (2003). Operant responding for a visual reinforcer in rats is enhanced by noncontingent nicotine: implications for nicotine self-administration and reinforcement. Psychopharmacology (Berl) 169: 68-76.

Epping-Jordan MP, Picciotto MR, Changeux JP, Pich EM (1999). Assessment of nicotinic acetylcholine receptor subunit con- 
tributions to nicotine self-administration in mutant mice. Psychopharmacology (Berl) 147: 25-26.

Epping-Jordan MP, Watkins SS, Koob GF, Markou A (1998). Dramatic decreases in brain reward function during nicotine withdrawal. Nature 393: 76-79.

Fulton S, Woodside B, Shizgal P (2000). Modulation of brain reward circuitry by leptin. Science 287: 125-128.

Harrison AA, Gasparini F, Markou A (2002). Nicotine potentiation of brain stimulation reward reversed by $\mathrm{DH} \beta \mathrm{E}$ and $\mathrm{SCH} 23390$, but not by eticlopride, LY 314582 or MPEP in rats. Psychopharmacology (Berl) 160: 56-66.

Harvey SC, Luetje CW (1996). Determinants of competitive antagonist sensitivity on neuronal nicotinic receptor beta subunits. J Neurosci 16: 3798-3806.

Harvey SC, Maddox FN, Luetje CW (1996). Multiple determinants of dihydro-beta-erythroidine sensitivity on rat neuronal nicotinic receptor alpha subunits. J Neurochem 67: 1953-1959.

Herberg LJ, Blundell JE (1967). Lateral hypothalamus: hoarding behavior elicited by electrical stimulation. Science 155: 349-350.

Hughes JR (1994). Smoking and alcoholism. In: Cos JL, Hatsukami DK (eds). Behavioral Approaches to Addiction. Cahners Healthcare Communications: Belle Mead, New Jersey.

Irvine EE, Bagnalasta $M$, Marcon C, Motta C, Tessari M, File SE et al (2001). Nicotine self-administration and withdrawal: modulation of anxiety in the social interaction test in rats. Psychopharmacology (Berl) 153: 315-320.

Kenny PJ, Polis I, Koob GF, Markou A (2003). Low dose cocaine self-administration transiently increases but high dose cocaine persistently decreases brain reward function in rats. Eur $J$ Neurosci 17: 191-195.

Kornetsky C, Esposito RU (1979). Euphorigenic drugs: effects on the reward pathways of the brain. Fed Proc 38: 2473-2476.

Kornetsky C, Esposito RU, McLean S, Jacobson JO (1979). Intracranial self-stimulation thresholds: a model for the hedonic effects of drugs of abuse. Arch Gen Psychiatry 36: 289-292.

Lin D, Bruijnzeel AW, Schmidt P, Markou A (2002). Exposure to chronic mild stress alters thresholds for lateral hypothalamic stimulation reward and subsequent responsiveness to amphetamine. Neuroscience 114: 925-933.

Mansvelder HD, McGehee DS (2000). Long-term potentiation of excitatory inputs to brain reward areas by nicotine. Neuron 27: 349-357.

Markou A, Koob GF (1991). Postcocaine anhedonia. An animal model of cocaine withdrawal. Neuropsychopharmacology 4: 17-26.

Markou A, Koob GF (1992). Construct validity of a self-stimulation threshold paradigm: effects of reward and performance manipulations. Physiol Behav 51: 111-119.
Olausson P, Jentsch JD, Taylor JR (2003). Repeated nicotine exposure enhances reward-related learning in the rat. Neuropsychopharmacology 28: 1264-1271.

Olausson P, Jentsch JD, Taylor JR (2004a). Nicotine enhances responding with conditioned reinforcement. Psychopharmaco$\log y$ (Berl) 171: 173-178.

Olausson P, Jentsch JD, Taylor JR (2004b). Repeated nicotine exposure enhances responding with conditioned reinforcement. Psychopharmacology (Berl) 173: 98-104.

Olds J (1958). Satiation effects in self-stimulation of the brain. J Comp Physiol Psychol 51: 675-678.

Olds J, Milner PM (1954). Positive reinforcement produced by electrical stimulation of the septal area and other regions of rat brain. J Comp Physiol Psychol 47: 419-427.

Parker SL, Fu Y, McAllen K, Luo J, McIntosh JM, Lindstrom JM et al (2004). Up-regulation of brain nicotinic acetylcholine receptors in the rat during long-term self-administration of nicotine: disproportionate increase of the alpha6 subunit. $\mathrm{Mol}$ Pharmacol 65: 611-622.

Paterson NE, Markou A (2004). Prolonged nicotine dependence associated with extended access to nicotine self-administration in rats. Psychopharmacology (Berl) 173: 64-72.

Pellegrino LJ, Pellegrino AS, Cushman AJ (1979). A Stereotaxic Atlas of the Rat Brain. New York: Plenum Press.

Picciotto MR, Zoli M, Rimondini R, Lena C, Marubio LM, Pich EM et al (1998). Acetylcholine receptors containing the beta2 subunit are involved in the reinforcing properties of nicotine. Nature 391: 173-177.

Picciotto MR, Zoli M, Zachariou V, Changeux JP (1997). Contribution of nicotinic acetylcholine receptors containing the beta 2-subunit to the behavioural effects of nicotine. Biochem Soc Trans 25: 824-829.

Rice ME, Cragg SJ (2004). Nicotine amplifies reward-related dopamine signals in striatum. Nat Neurosci 7: 583-584.

Shoaib M, Swanner LS, Yasar S, Goldberg SR (1999). Chronic caffeine exposure potentiates nicotine self-administration in rats. Psychopharmacology (Berl) 142: 327-333.

Tapper AR, McKinney SL, Nashmi R, Schwarz J, Deshpande P, Labarca $C$ et al (2004). Nicotine activation of alpha $4^{*}$ receptors: sufficient for reward, tolerance, and sensitization. Science 306: 1029-1032.

Watkins SS, Stinus L, Koob GF, Markou A (2000). Reward and somatic changes during precipitated nicotine withdrawal in rats: centrally and peripherally mediated effects. J Pharmacol Exp Ther 292: 1053-1064.

Wise RA (1996). Addictive drugs and brain stimulation reward. Annu Rev Neurosci 19: 319-340.

Wise RA, Yokel RA, Hansson PA, Gerber GJ (1977). Concurrent intracranial self-stimulation and amphetamine self-administration in rats. Pharmacol Biochem Behav 7: 459-461. 